\title{
ANALISIS SIFAT FISIK TANAH DI DESA NDETU NDORA 1 KECAMATAN ENDE KABUPATEN ENDE
}

\author{
Fransiskus Rocky Sanggu
}

PT. Gunta Samba Jaya Indogunta Group, Merapun, Kec. Kelay, Kabupaten Berau, Kalimantan Timur 77362

franssanggu@gmail.com

\begin{abstract}
Analysis of physical properties of land in Village Ndetu Ndora 1 Sub-district of Ende, Ende District. This study aims to determine the Physical Properties of Soil in Ndetu Ndora I Village, Ende District, Ende Regency. Research is exploratory research, by evaluating physical properties, evaluation results are described and compared with existing physical and chemical soil standards. The results showed that the texture of the soil consisted of clay and dusty clay. In structure, the type that exists is the structure of angular lumps, rounded lumps, granular, and crumbs. In soil, color is dominant by very dark brown, dark brown, very dark gray, very dark grayish brown. Soil consistency, it appears that these soils have a sticky, plastic, loose, softly consistence. The $\mathrm{pH}$ in the soil ranges from 4.8 to 6.4 . And the slope is in the range of $13 \%-23 \%$.
\end{abstract}

Keywords : Analysis, physical and chemical properties of the soil

\section{PENDAHULUAN}

Desa Ndetu Ndora I adalah salah satu desa yang ada di Kabupaten Ende. Desa ini merupakan salah satu desa yang memproduksi ubi kayu yang sangat khas yang dikenal dengan sebutan ubi nuabosi. Para petani di daerah ini memiliki beberapa komoditi pertanian selain ubi nuabosi. Komoditi pertanian yang ada selain ubi adalah advokat, mangga, jambu biji, bawang putih, wortel, buncis, kacang panjang, cabai besar, tomat, terung, labu siam, cabai rawit, jahe, kencur, kunyit, dan cengkeh (Kota Ende Dalam Angka, 2015). Dalam pembudidayaan tanaman pertanian salah satu syarat utama agar memperoleh

produksi yang optimal adalah kondisi tanah yang subur.

Kesuburan tanah adalah
kemampuan suatu tanah untuk
menghasilkan produk tanaman yang
diinginkan pada lingkungan tempat
tanah itu berada. Produk tanaman
tersebut dapat berupa: buah, biji, daun,
bunga, umbi, getah, eksudat, akar,
trubus, batang, biomassa, naungan atau
penampilan. Kesuburan tanah
merupakan faktor penting yang dapat
mendukung pertumbuhan dan
perkembangan tanaman. Kesuburan
tanah dapat dilihat dari berbagai aspek,
yaitu kesuburan fisik, kimia dan biologi.
Kesuburan biologi tanah berkaitan
dengan semua makhluk hidup yang ada


di dalam tanah. Biologi tanah adalah ilmu yang mempelajari makhlukmakhluk hidup di dalam tanah, contohnya akar tanaman dan organisme lainnya di dalam tanah. Kesuburan kimia tanah berkaitan dengan semua unsurunsur yang terdapat di dalam tanah, reaksinya serta sifat-sifat kimia lainnya yang terjadi di dalam tanah. Beberapa sifat kimia tanah adalah $\mathrm{pH}$ tanah, kandungan karbon organik, kandungan nitrogen, rasio karbon dan nitrogen $(\mathrm{C} / \mathrm{N})$, kandungan fosfor tanah yang terdiri dari: P-tersedia dan P-total tanah, kandungan kation asam, kejenuhan basa (KB) dan kapasitas tukar kation (KTK). Selain sifat biologi dan kimia tanah, kesuburan tanah juga sangat dipengaruhi oleh sifat fisik dari tanah tersebut.

Sifat fisik tanah merupakan ciriciri dari tanah tersebut yang dapat diamati di lapangan. Sifat fisik tanah ini dilihat dari berbagai aspek dan sangat mempengaruhi kinerja dari sifat kimia dan biologi tanah. Sifat fisik tanah terdiri dari tekstur tanah, struktur tanah, warna tanah, porositas tanah, kerapatan isi tanah dan konsistensi tanah.

Tekstur tanah merupakan perbandingan relatif partikel-partikel primer tanah. Partikel primer tanah terdiri dari tiga jenis yaitu pasir, debu dan liat. Suatu fraksi atau partikel yang dominan pada suatu tanah akan menentukan ciri dan jenis tanah yang bersangkutan. Struktur tanah adalah agregasi atau gabungan partikel-partikel tanah yang membentuk suatu agregat. Struktur ini terjadi karena butir-butir pasir, debu dan liat terikat satu sama lain oleh suatu perekat seperti lahan organik, oksida-oksida besi dan lain-lain.
Warna tanah adalah sifat tanah yang dapat digunakan dengan mudah dalam menilai sifat tanah secara umum. Warna tanah berhubungan langsung secara proporsional dari total campuran warna yang dipantulkan permukakan tanah. Warna tanah sangat ditentukan oleh luas permukaan spesifik yang dikali dengan proporsi volumetrik masingmasing terhadap tanah.

Porositas adalah ruang kosong (pori-pori) diantara tekstur tanah yang tidak terisi dengan mineral atau bahan organik namun terisi oleh gas atau air. Semakin tinggi kepadatan tanah maka semakin rendah porositasnya dan sebaliknya semakin rendah kepadatan tanah semakin rendah porositasnya. Idealnya total porositas dari tanah adalah sekitar 50\% dari total volume tanah.

Bobot isi tanah merupakan kerapatan tanah per satuan volume yang dinyatakan dalam dua batasan berikut ini: 1) Kerapatan partikel (bobot partikel = BP) adalah bobot massa partikel padat per satuan volume tanah, biasanya tanah mempunyai kerapatan partikel 2,6 gram $\mathrm{cm}^{-3}$ dan 2) Kerapatan massa (bobot isi = BI) adalah bobot massa tanah kondisi lapangan yang dikering-ovenkan per satuan volume. Nilai kerapatan massa tanah berbanding lurus dengan tingkat kekasaran partikel-partikel tanah, makin kasar akan makin berat. Konsistensi tanah berarti kemampuan tanah untuk menempel pada objek lain dan kemampuan tanah untuk menghindari deformasi atau berpisah. Konsistensi diukur dengan 3 kondisi kelembapan yaitu: kering, lembap dan basah. Konsistensi tanah bergantung pada tingkat banyaknya tanah liat. 
Sifat-sifat tanah yang mendukung pertumbuhan dan produksi tanaman perlu diketahui nilainya, agar dapat melakukan langkah-langkah pengelolaan yang tepat. Cara yang dapat dilakukan agar dapat mengetahui sifat fisik tanah adalah dengan menganalisis tanah tersebut. Analisis sifat fisik tanah dapat dilakukan dengan cara kualitatif, yaitu dengan langsung mengidentifikasi sifat fisik tanah tersebut di lapangan. Berdasarkan pernyataan di atas, maka perlu dilakukan penelitian dengan judul "Analisis Sifat Fisik Tanah di Desa Ndetu Ndora I Kecamatan Ende Kabupaten Ende". Penelitian ini bertujuan untuk Mengetahui Sifat Fisik Tanah yang ada di Desa Ndetu Ndora I, Kecamatan Ende, Kabupaten Ende.

\section{METODE PENELITIAN}

Kegiatan eksplorasi dilakukan pada areal pertanian di Dusun Nuabosi yang ada di Desa Ndetu Ndora I, Kecamatan Ende, Kabupaten Ende. Penelitian dilakukan mulai bulan Maret sampai April Tahun 2017. Bahan yang digunakan dalam penelitian ini adalah tanah sebagai media penelitian dan larutan $\mathrm{H}_{2} \mathrm{O}_{2}$. Peralatan yang digunakan yaitu linggis, cangkul, skop, parang, sabit, ember, penggaru, meter, timbangan, mistar, $\mathrm{pH}$ meter, ring sampel, buku munsel dan alat tulis.

\section{Pelaksanaan Penelitian}

\section{Penentuan Lokasi}

Pemilihan lokasi penelitian ditentukan dengan metode cluster sampel. Dimana sebelumnya dilakukan survei lokasi untuk menentukan lokasi mana yang memenuhi syarat untuk dijadikan sampel lokasi penelitian yaitu lahan pertanian petani. Teknik penelitian yang dilakukan pengambilan sampel tanah dan luasan lahan disesuaikan dengan luasan yang ada di lokasi.

\section{Teknik Pengambilan Sampel}

Teknik pengambilan sampel tanah ini dengan menggunakan kantong plastik dan diambil lima titik sampel pada lahan secara acak. Setiap titik yang sudah ditentukan digali tanahnya dengan kedalaman $\pm 20 \mathrm{~cm}$. Selanjutnya sampel tanah tersebut pada setiap perlakuan yang sama dicampur atau dikomposit.

\section{Variabel Pengamatan}

\section{Tekstur Tanah}

Tekstur tanah dianalisis dengan metode kualitatif. Tanah yang akan ditentukan teksturnya dibasahi, kemudian dipirid dengan ibu jari dan telunjuk. Setelah tanah tersebut telah membentuk pita, maka dirasakan kasar, licin dan lengket. Tanah yang telah dirasakan tersebut dicatat, lalu disesuaikan dengan tabel penetapan kelas tekstur tanah di lapang.

\section{Struktur Tanah}

Struktur tanah dianalisis dengan metode kualitatif. Tanah yang akan ditentukan struktur diambil dalam bentuk bongkahan, kemudian diamati bentuknya dan tingkat perkembangan struktur.

\section{Konsistensi Tanah}

Penentuan konsistensi tanah harus disesuaikan dengan kandungan air tanah yaitu dalam keadaan basah, lembab atau kering. Tanah basah: kandungan air di atas kapasitas lapang. Tanah lembab: kandungan air mendekati kapasitas lapang dan Tanah kering: tanah dalam keadaan kering angin. 


\section{Warna Tanah}

Cara menentukan warna tanah adalah dengan membandingkan warna tanah dengan warna pembanding dalam kartu Munsell Soil Color Chart, dengan mendekatkan contoh tanah atau memasukkan contoh tanah ke dalam lubang yang telah tersedia di dekat masing-masing kertas warna pembanding. Penulisan warna ditulis menurut urutan hue, value, chrome, misalnya 10 YR $3 / 4$ (coklat).

\section{Analisis Data}

Sampel tanah yang diambil dianalisis secara kualitatif untuk mendapatkan data sifat fisik tanah. Data sifat fisik tanah yang telah didapat dianalisis secara deskriptif untuk menggambarkan sifat fisik, lalu dideskripsikan dengan membandingkan dengan kriteria sifat tanah.

\section{HASIL DAN PEMBAHASAN}

Sifat fisik tanah pada lahan-lahan yang terdapat di Dusun Nuabosi, Desa Ndetu Ndora I yang diamati yaitu tekstur, struktur, konsistensi, warna tanah, $\mathrm{pH}$ tanah dan kemiringan lereng. Hasil analisis sifat-sifat tanah tersebut menunjukan karakteristik dan kesuburan dari lahan yang ada di Dusun Nuabosi, Desa Ndetu Ndora I, Kecamatan Ende, Kabupaten Ende. Analisis sifat tanah ini diambil dari 50 titik sampel yang ada di Dusun Nuabosi, Desa Ndetu Ndora I. hasil analisis disajikan pada Tabel 1 di bawah ini.

Tabel 1. Hasil Analisis sifat fisik tanah

\begin{tabular}{ll}
\hline Sifat Fisik Tanah & \multicolumn{1}{c}{ Karakteristik } \\
\hline Tekstur & Lempung dan lempung berdebu \\
Struktur & Gumpal bersudut, gumpal membulat, granular, dan remah \\
Konsistensi & Lekat, plastis, gembur, lunak \\
Warna Tanah & Very dark brown, dark brown, very dark gray, very dark \\
& grayish brown \\
pH Tanah & $4,2-6,2$ \\
Kemiringan Lereng & $16 \%-28 \%$ \\
\hline
\end{tabular}

\section{Tekstur}

Tekstur tanah menggambarkan persentase (berdasarkan berat) dari ketiga komponen penyusun fraksi mineral tanah, yakni pasir (sand), debu (silt) dan liat (clay). Ketiga fraksi tanah ini dibedakan satu sama lain oleh diameter partikel yang bersangkutan. Bagi partikel yang berbentuk tidak bulat dianggap memiliki diameter yang sama dengan rerata antara ukuran maksimum dan minimumnya. Penaman tekstur tanah menggunakan kata-kata seperti pasir (sand), lempung (loam), liat (clay) dan debu (silt). Lempung menunjukkan campuran antara pasir, debu dan liat pada perbandingan yang hampir sama.

Tekstur tanah yang didapat dari hasil analisis tanah di Dusun Nuabosi, Desa Ndetu Ndora I adalah lempung dan lempung berdebu. Tekstur tanah menggambarkan persentase (berdasarkan 
berat) dari ketiga komponen penyusun fraksi mineral tanah, yakni pasir (sand), lempung (loam), liat (clay) dan debu (silt). Ketiga fraksi tanah ini dibedakan satu sama lain oleh diameter partikel yang bersangkutan. Sedangkan tekstur lempung adalah tekstur dengan komposisi partikel pasir, debu dan liat yang berada dalam kondisi seimbang.

Tekstur tanah erat hubungannya dengan kekerasan, permeabilitas, plastisitas, kesuburan dan produktivitas tanah pada daerah tertentu. Tekstur tanah adalah perbandingan relatif antara fraksifraksi debu, liat dan pasir dalam bentuk persen. Tekstur tanah dapat berfungsi menentukan tata air di dalam tanah yaitu berupa penetrasi, kecepatan infiltrasi, serta kemampuan mengikat air. Kelas tekstur dari sampel-sampel tanah yang diambil di Dusun Nuabosi, Desa Ndetu Ndora I disajikan pada Tabel 2.

Tabel 2. Hasil analisis tekstur tanah

\begin{tabular}{cccc}
\hline No. Sampel & Tekstur Tanah & No. Sampel & Tekstur Tanah \\
\hline L.1.1.2 & Lempung & L.2.13.2 & Lempung \\
L.1.2.2 & Lempung & L.3.1.2 & Lempung \\
L.1.3.2 & Lempung & L.3.2.2 & Lempung \\
L.1.4.2 & Lempung & L.3.3.2 & Lempung \\
L.1.5.2 & Lempung & L.3.4.2 & Lempung \\
L.1.6.2 & Lempung & L.3.5.2 & Lempung \\
L.1.7.2 & Lempung & L.3.6.2 & Lempung \\
L.1.8.2 & Lempung & L.3.7.2 & Lempung \\
L.1.9.2 & Lempung & L.3.8.2 & Lempung \\
L.1.10.2 & Lempung & L.3.9.2 & Lempung \\
L.1.11.2 & Lempung & L.3.10.2 & Lempung \\
L.1.12.2 & Lempung & L.3.11.2 & Lempung \\
L.1.13.2 & Lempung berdebu & L.3.12.2 & Lempung \\
L.2.1.2 & Lempung berdebu & L.3.13.2 & Lempung \\
L.2.2.2 & Lempung berdebu & L.4.1.2 & Lempung \\
L.2.3.2 & Lempung berdebu & L.4.2.2 & Lempung \\
L.2.4.2 & Lempung berdebu & L.4.3.2 & Lempung \\
L.2.5.2 & Lempung berdebu & L.4.4.2 & Lempung \\
L.2.6.2 & Lempung berdebu & L.4.5.2 & Lempung \\
L.2.7.2 & Lempung berdebu & L.4.6.2 & Lempung \\
L.2.8.2 & Lempung berdebu & L.4.7.2 & Lempung \\
L.2.9.2 & Lempung & L.4.8.2 & Lempung \\
L.2.10.2 & Lempung & L.4.9.2 & Lempung \\
L.2.11.2 & Lempung & L.4.10.2 & Lempung \\
L.2.12.2 & Lempung & L.4.11.2 & Lempung \\
\hline & & &
\end{tabular}


kation, dan mikroorganisme. Bila terjadi kerusakan pada tanah maka diperlukan perbaikan tanah agar tanaman dapat tumbuh dengan baik, seperti pada tanah podzolik dilakukan dengan memperbaiki kandungan organiknya, meningkatkan unsur hara seperti fosfor dari oksida Fe dan Al. Selain itu, juga memperbaiki sifat fisik dan stuktur tanahnya dan membentuk senyawa kompleks dengan unsur mikro sehingga mengurangi proses pencucian sulfur (Anonim, 2005).

Tabel 3. Hasil Analisis Struktur Tanah

\begin{tabular}{cccc}
\hline No. Sampel & Struktur Tanah & No. Sampel & Struktur tanah \\
\hline L.1.1.2 & Gumpal membulat & L.2.13.2 & Gumpal membulat \\
L.1.2.2 & Gumpal bersudut & L.3.1.2 & Gumpal membulat \\
L.1.3.2 & Gumpal membulat & L.3.2.2 & Gumpal membulat \\
L.1.4.2 & Gumpal membulat & L.3.3.2 & Gumpal membulat \\
L.1.5.2 & Gumpal membulat & L.3.4.2 & Gumpal membulat \\
L.1.6.2 & Gumpal membulat & L.3.5.2 & Gumpal membulat \\
L.1.7.2 & Gumpal membulat & L.3.6.2 & Gumpal membulat \\
L.1.8.2 & Gumpal membulat & L.3.7.2 & Gumpal membulat \\
L.1.9.2 & Gumpal bersudut & L.3.8.2 & Gumpal membulat \\
L.1.10.2 & Gumpal membulat & L.3.9.2 & Remah \\
L.1.11.2 & Gumpal membulat & L.3.10.2 & Granuler \\
L.1.12.2 & Gumpal membulat & L.3.11.2 & Remah \\
L.1.13.2 & Gumpal bersudut & L.3.12.2 & Gumpal membulat \\
L.2.1.2 & Gumpal bersudut & L.3.13.2 & Gumpal membulat \\
L.2.2.2 & Gumpal bersudut & L.4.1.2 & Gumpal membulat \\
L.2.3.2 & Gumpal membulat & L.4.2.2 & Gumpal membulat \\
L.2.4.2 & Gumpal bersudut & L.4.3.2 & Gumpal membulat \\
L.2.5.2 & Gumpal bersudut & L.4.4.2 & Gumpal membulat \\
L.2.6.2 & Gumpal bersudut & L.4.5.2 & Gumpal membulat \\
L.2.7.2 & Gumpal bersudut & L.4.6.2 & Gumpal membulat \\
L.2.8.2 & Gumpal bersudut & L.4.7.2 & Gumpal membulat \\
L.2.9.2 & Gumpal membulat & L.4.8.2 & Gumpal membulat \\
L.2.10.2 & Gumpal membulat & L.4.9.2 & Gumpal membulat \\
L.2.11.2 & Gumpal membulat & L.4.10.2 & Gumpal membulat \\
L.2.12.2 & Gumpal membulat & L.4.11.2 & Gumpal membulat \\
\hline & & &
\end{tabular}

Struktur tanah pada lapisan atas sangat penting artinya bagi dunia pertanian. Hal ini karena struktur tanah sangat mempengaruhi aerasi tanah, permeabilitas air, ketahanan tanah terhadap erosi dan peran tanah sebagai media perkecambahan tanaman. Struktur tanah yang diperoleh dari hasil penelitian di Dusun Nuabosi, Desa Ndetu Ndora I adalah gumpal membulat dan bersudut.
Struktur tanah dari sampel-sampel tanah yang diambil di Dusun Nuabosi, Desa Ndetu Ndora I disajikan pada Tabel 3.

Struktur tanah merupakan gumpalan-gumpalan kecil dari tanah sebagai akibat melekatnya butir-butir tanah satu sama lain. Satu unit struktur tanah disebut ped. Apabila unit-unit struktur tanah tersebut tidak terbentuk maka dikatakan bahwa tanah tersebut 
tidak berstruktur. Dalam hal ini ada dua kemungkinan yaitu, 1) butir tunggal (single grain) yaitu butir-butir tanah tidak melekat satu sama lain, contoh tanah pasir; 2) Pejal atau massive yaitu jika butir-butir tanah melekat satu sama lain dengan kuat sehingga tidak membentuk gumpalan-gumpalan (ped). Penyipatan struktur tanah meliputi 3 hal yaitu bentuk, tingkat perkembangan dan ukuran.

\section{Konsistensi}

Konsistensi tanah adalah daya kohesi dan adhesi diantara partikel- partikel tanah dan ketahanan (resistensi) massa tanah tersebut terhadap perubahan bentuk oleh tekanan atau berbagai kekuatan yang dapat mempengaruhi. Konsistensi tanah dapat dikelompokkan menjadi dua yaitu: kualitatif dan kuantitatif dengan pendekatan angkaangka Atteberg. Penentuan konsistensi tanah ini mempunyai hubungan antara kadar lengas dan konsistensi tanah. Konsistensi tanah dari sampel-sampel tanah yang diambil di Dusun Nuabosi, Desa Ndetu Ndora I disajikan pada Tabel 4.

Tabel 4. Hasil Analisis Konsistensi Tanah

\begin{tabular}{|c|c|c|c|c|c|c|c|c|c|}
\hline \multirow{3}{*}{$\begin{array}{c}\text { No. } \\
\text { Sampel }\end{array}$} & \multicolumn{4}{|c|}{ Konsistensi } & \multirow{3}{*}{$\begin{array}{c}\text { No. } \\
\text { Sampel }\end{array}$} & \multicolumn{4}{|c|}{ Konsistensi } \\
\hline & \multicolumn{2}{|c|}{ Tanah Basah } & \multirow{2}{*}{$\begin{array}{c}\text { Tanah } \\
\text { Lembab }\end{array}$} & \multirow{2}{*}{$\begin{array}{l}\text { Tanah } \\
\text { Kering }\end{array}$} & & \multicolumn{2}{|c|}{ Tanah Basah } & \multirow{2}{*}{$\begin{array}{c}\text { Tanah } \\
\text { Lembab }\end{array}$} & \multirow{2}{*}{$\begin{array}{l}\text { Tanah } \\
\text { Kering }\end{array}$} \\
\hline & Kelekatan & Plastisitas & & & & Kelekatan & Plastisitas & & \\
\hline L.1.1.2 & Lekat & Plastis & Gembur & Lunak & L.2.13.2 & Lekat & Plastis & Gembur & Lekat \\
\hline L.1.2.2 & Lekat & Plastis & Gembur & Lunak & L.3.1.2 & Lekat & Plastis & Gembur & Lekat \\
\hline L.1.3.2 & Lekat & Plastis & Gembur & Lunak & L.3.2.2 & Lekat & Plastis & Gembur & Lekat \\
\hline L.1.4.2 & Lekat & Plastis & Gembur & Lunak & L.3.3.2 & Lekat & Plastis & Gembur & Lekat \\
\hline L.1.5.2 & Lekat & Plastis & Gembur & Lunak & L.3.4.2 & Lekat & Plastis & Gembur & Lekat \\
\hline L.1.6.2 & Lekat & Plastis & Gembur & Lunak & L.3.5.2 & Lekat & Plastis & Gembur & Lekat \\
\hline L.1.7.2 & Lekat & Plastis & Gembur & Lunak & L.3.6.2 & Lekat & Plastis & Gembur & Lekat \\
\hline L.1.8.2 & Lekat & Plastis & Gembur & Lunak & L.3.7.2 & Lekat & Plastis & Gembur & Lekat \\
\hline L.1.9.2 & Lekat & Plastis & Gembur & Lunak & L.3.8.2 & Lekat & Plastis & Gembur & Lekat \\
\hline L. 1.10 .2 & Lekat & Plastis & Gembur & Lunak & L.3.9.2 & Lekat & Plastis & Gembur & Lekat \\
\hline L.1.11.2 & Lekat & Plastis & Gembur & Lunak & L.3.10.2 & Lekat & Plastis & Gembur & Lekat \\
\hline L.1.12.2 & Lekat & Plastis & Gembur & Lunak & L.3.11.2 & Lekat & Plastis & Gembur & Lekat \\
\hline L.1.13.2 & Lekat & Plastis & Gembur & Lunak & L.3.12.2 & Lekat & Plastis & Gembur & Lekat \\
\hline L.2.1.2 & Lekat & Plastis & Gembur & Lunak & L.3.13.2 & Lekat & Plastis & Gembur & Lekat \\
\hline L.2.2.2 & Lekat & Plastis & Gembur & Lunak & L.4.1.2 & Lekat & Plastis & Gembur & Lekat \\
\hline L.2.3.2 & Lekat & Plastis & Gembur & Lunak & L.4.2.2 & Lekat & Plastis & Gembur & Lekat \\
\hline L.2.4.2 & Lekat & Plastis & Gembur & Lunak & L.4.3.2 & Lekat & Plastis & Gembur & Lekat \\
\hline L.2.5.2 & Lekat & Plastis & Gembur & Lunak & L. 4.4 .2 & Lekat & Plastis & Gembur & Lekat \\
\hline L.2.6.2 & Lekat & Plastis & Gembur & Lunak & L.4.5.2 & Lekat & Plastis & Gembur & Lekat \\
\hline L.2.7.2 & Lekat & Plastis & Gembur & Lunak & L.4.6.2 & Lekat & Plastis & Gembur & Lekat \\
\hline L.2.8.2 & Lekat & Plastis & Gembur & Lunak & L.4.7.2 & Lekat & Plastis & Gembur & Lekat \\
\hline L.2.9.2 & Lekat & Plastis & Gembur & Lunak & L. 4.8 .2 & Lekat & Plastis & Gembur & Lekat \\
\hline L.2.10.2 & Lekat & Plastis & Gembur & Lunak & L.4.9.2 & Lekat & Plastis & Gembur & Lekat \\
\hline L.2.11.2 & Lekat & Plastis & Gembur & Lunak & L. 4.10 .2 & Lekat & Plastis & Gembur & Lekat \\
\hline L. 2.12 .2 & Lekat & Plastis & Gembur & Lunak & L.4.11.2 & Lekat & Plastis & Gembur & Lekat \\
\hline
\end{tabular}


Konsistensi suatu tanah itu sangat penting karena apabila lahan pertanian diketahui konsistensi tanahnya akan mudah diolah dan perlakuan terhadap tanah pertanian bisa sesuai dan mendapatkan hasil pertanian bisa sesuai dan mendapatkan hasil pertanian yang maksimal. Pada kondisi kering, konsistensi tanah diukur berdasarkan tingkat kekerasannya, yakni tanah yang lepas, lunak, agak keras, keras, sangat keras atau keras sekali. Kekerasan ini berkaitan erat dengan kandungan liat tanah. Pada tanah lembab, konsistensi tanah diukur berdasarkan tingkat kepadatannya, yakni tanah yang lepas, sangat remah, remah, padat, sangat padat atau padat sekali.

Pentingnya konsistensi tanah ialah untuk menentukan cara penggarapan tanah yang efisien dan penetrasi akar tanaman di lapisan tanah bawahan. Tanah yang bertekstur pasir bersifat tidak lengket, tidak liat (non plastic) dan lepas-lepas. Sebaliknya tanah bertekstur lempung-berat pada keadaan basah berkonsistensi sangat lengket, sangat liat dan bila kering bersifat sangat teguh (kuat) dan keras.

Tabel 5. Hasil Analisis Warna Tanah

\begin{tabular}{|c|c|c|c|}
\hline No. Sampel & Warna tanah & No. Sampel & Warna tanah \\
\hline L.1.1.2 & $10 y r 3 / 3$ dark brown & L.2.13.2 & $10 y r 2 / 1$ black \\
\hline L.1.2.2 & $10 \mathrm{yr} 3 / 3$ dark brown & L.3.1.2 & $7,5 \mathrm{yr} 2,5 / 1$ black \\
\hline L.1.3.2 & $7,5 \mathrm{yr} 2,5 / 2$ very dark brown & L.3.2.2 & $10 \mathrm{yr} 3 / 2$ very dark grayish brown \\
\hline L.1.4.2 & $7,5 \mathrm{yr} 2,5 / 2$ very dark brown & L.3.3.2 & $10 y r 3 / 2$ very dark grayish brown \\
\hline L.1.5.2 & $10 \mathrm{yr} 3 / 2$ very dark grayish brown & L.3.4.2 & $10 y r 3 / 2$ very dark grayish brown \\
\hline L.1.6.2 & $7,5 \mathrm{yr} 2,5 / 2$ very dark brown & L.3.5.2 & $10 \mathrm{yr} 3 / 2$ very dark grayish brown \\
\hline L.1.7.2 & $7,5 y r 2,5 / 2$ very dark brown & L.3.6.2 & $7,53 / 1$ very dark brown \\
\hline L.1.8.2 & $7,5 \mathrm{yr} 2,5 / 2$ very dark brown & L.3.7.2 & $7,52,5 / 3$ very dark brown \\
\hline L.1.9.2 & $7,5 \mathrm{yr} 2,5 / 2$ very dark brown & L.3.8.2 & $7,52,5 / 3$ very dark brown \\
\hline L.1.10.2 & $7,5 \mathrm{yr} 2,5 / 2$ very dark brown & L.3.9.2 & $7,52,5 / 3$ very dark brown \\
\hline L.1.11.2 & 7,5 yr $2,5 / 2$ very dark brown & L.3.10.2 & $7,5 \mathrm{yr} 3 / 4$ dark brown \\
\hline L.1.12.2 & $7,5 \mathrm{yr} 2,5 / 2$ very dark brown & L.3.11.2 & $7,5 \mathrm{yr} 4,6$ strong brown \\
\hline L.1.13.2 & $7,5 \mathrm{yr} 2,5 / 2$ very dark brown & L.3.12.2 & $7,5 y r 2 / 3$ dark brown \\
\hline L.2.1.2 & $7,5 \mathrm{yr} 2,5 / 2$ very dark brown & L.3.13.2 & $7,5 y r 3 / 4$ dark brown \\
\hline L.2.2.2 & $7,5 y r 3 / 3$ dark brown & L.4.1.2 & $7,5 y r 3 / 4$ dark brown \\
\hline L.2.3.2 & 7,5 yr $3 / 3$ dark brown & L. 4.2 .2 & $7,5 y r 3 / 4$ dark brown \\
\hline L.2.4.2 & $7,5 \mathrm{yr} 2,5 / 2$ very dark brown & L.4.3.2 & 7,5yr 3/4 dark brown \\
\hline L.2.5.2 & $7,5 y r 3 / 4$ dark brown & L.4.4.2 & $7,5 \mathrm{yr} 3 / 3$ dark brown \\
\hline L.2.6.2 & $7,5 \mathrm{yr} 3 / 4$ dark brown & L.4.5.2 & $7,5 \mathrm{yr} 3 / 3$ dark brown \\
\hline L.2.7.2 & $7,5 \mathrm{yr} 2,5 / 2$ very dark brown & L. 4.6 .2 & $7,5 \mathrm{yr} 3 / 4$ dark brown \\
\hline L.2.8.2 & $10 \mathrm{yr} 3 / 3$ dark brown & L.4.7.2 & $7,5 y r 3 / 2$ dark brown \\
\hline L.2.9.2 & $7,5 \mathrm{yr} 2,5 / 2$ very dark brown & L. 4.8 .2 & $7,5 y r 3 / 2$ dark brown \\
\hline L. 2.10 .2 & $10 y r 3 / 2$ verydark grayish & L.4.9.2 & $7,5 \mathrm{yr} 2,5 / 3$ very dark brown \\
\hline L.2.11.2 & $10 \mathrm{yr} 2,5 / 2$ very dark brown & L. 4.10 .2 & $7,5 \mathrm{yr} 3 / 2$ dark brown \\
\hline L.2.12.2 & $7,5 \mathrm{yr} 3 / 1$ very dark brown & L.4.11.2 & $7,5 \mathrm{yr} 2,5 / 3$ very dark brown \\
\hline
\end{tabular}




\section{Warna Tanah}

Warna merupakan satu dari sifatsifat tanah yang mudah untuk diamati. Walaupun warna mempunyai pengaruh yang kecil terhadap kegunaan tanah, tetapi kadang-kadang dapat dijadikan petunjuk adanya sifat-sifat khusus dari tanah. Misalnya, warna tanah gelap mencirikan kandungan bahan organik tinggi. Warna kelabu menunjukkan bahwa tanah sudah mengalami pelapukan lanjut. Warna tanah ditentukan dengan cara membandingkan dengan warna baku yang terdapat pada "Munsell Soil Color Chart". Penentuan ini meliputi penetapan warna dasar tanah (matriks), warna bidang struktur dan selaput liat, warna karatan dan konkresi, warna plintit dan warna humus.

Warna tanah merupakan sifat yang penting sebab sifat ini erat kaitannya dengan kandungan bahan organik, iklim, drainase serta mineral yang dikandung oleh tanah. Warna mineral tanah biasanya putih atau agak kelabu, sekalipun beberapa mineral memiliki warna lain misalnya hitam, merah dan sebagainya. Horizon A2 memiliki warna yang paling dekat dengan warna mineral asli penyusun tanah yang bersangkutan. Secara langsung mempengaruhi penyerapan sinar matahari dan salah satu faktor penentu suhu tanah. Secara tidak langsung berhubungan dengan sifat-sifat tanah, misalnya informasi subsoil drainase, kandungan bahan organik surface horizon, pembeda antar horison. Diukur dengan menggunakan standar warna (Soil Munsell Color Chart). Warna tanah dari sampel-sampel tanah yang diambil di Desa Detundora II disajikan pada Tabel 5.

\section{Kemiringan Lereng}

Kemiringan lereng merupakan ukuran kemiringan lahan relative terhadap bidang datar yang secara umum dinyatakan dalam persen atau derajat. Kecuraman lereng, panjang lereng dan bentuk lereng semuanya akan mempengaruhi besarnya erosi dan aliran permukaan. Menurut sitanala Arsyaf mengkelaskan lereng menjadi seperti berikut:

Tabel 6. Kelas Kemiringan Lereng

\begin{tabular}{ccc}
\hline Kemiringan Lereng $\left(^{\mathbf{0}}\right.$ ) & Kemiringan (\%) & Klasifikasi \\
\hline$<1$ & $0-2$ & Datar-hampir datar \\
$1-3$ & $3-7$ & Sangat landai \\
$3-6$ & $8-13$ & Landai \\
$6-9$ & $14-20$ & Agak curam \\
$9-25$ & $21-55$ & Curam \\
$25-26$ & $56-140$ & Sangat curam \\
$>65$ & $>140$ & Terjal \\
\hline
\end{tabular}

United Stated Soil System Management

Hasil pengukuran kemiringan lereng yang ada di Desa Detundora I menunjukkan bahwa lahan-lahan yang ada di Desa tersebut mempunyai bentukan kemiringan lereng yang sangat bervariasi. Dalam klasifikasi kemiringan lereng, maka Desa Detundora I mempunyai klasifikasi agak curam 
hingga curam. Hal ini terlihat dari nilai

pengelolaan lahan yang tepat agar kemiringan lereng yang berada pada permasalahan kecuraman ini tidak $13 \%$ sampai $23 \%$. Untuk itu perlu mengurangi kesuburan tanah.

Tabel 7. Kemiringan Lereng di Desa Detundora I

\begin{tabular}{|c|c|c|c|}
\hline No. Sampel & Kemiringan Lereng (\%) & No. Sampel & Kemiringan Lereng (\%) \\
\hline L.1.1.2 & 18 & L.2.13.2 & 18 \\
\hline L.1.2.2 & 23 & L.3.1.2 & 19 \\
\hline L.1.3.2 & 28 & L.3.2.2 & 21 \\
\hline L.1.4.2 & 26 & L.3.3.2 & 20 \\
\hline L.1.5.2 & 25 & L.3.4.2 & 20 \\
\hline L.1.6.2 & 22 & L.3.5.2 & 22 \\
\hline L.1.7.2 & 22 & L.3.6.2 & 25 \\
\hline L.1.8.2 & 23 & L.3.7.2 & 27 \\
\hline L.1.9.2 & 18 & L.3.8.2 & 28 \\
\hline L. 1.10 .2 & 25 & L.3.9.2 & 27 \\
\hline L.1.11.2 & 22 & L.3.10.2 & 23 \\
\hline L.1.12.2 & 22 & L.3.11.2 & 25 \\
\hline L.1.13.2 & 22 & L.3.12.2 & 23 \\
\hline L.2.1.2 & 21 & L.3.13.2 & 24 \\
\hline L.2.2.2 & 22 & L.4.1.2 & 14 \\
\hline L.2.3.2 & 19 & L.4.2.2 & 27 \\
\hline L.2.4.2 & 21 & L.4.3.2 & 17 \\
\hline L.2.5.2 & 19 & L.4.4.2 & 23 \\
\hline L.2.6.2 & 23 & L.4.5.2 & 27 \\
\hline L.2.7.2 & 17 & L.4.6.2 & 24 \\
\hline L.2.8.2 & 20 & L.4.7.2 & 26 \\
\hline L.2.9.2 & 22 & L.4.8.2 & 26 \\
\hline L.2.10.2 & 20 & L.4.9.2 & 24 \\
\hline L.2.11.2 & 16 & L. 4.10 .2 & 28 \\
\hline L.2.12.2 & 19 & L. 4.11 .2 & 21 \\
\hline
\end{tabular}

\section{pH Tanah}

Keasaman atau $\mathrm{pH}$ (potential of Hidrogen) adalah nilai (pada skala 0-14) yang menggambarkan jumlah relatif ion $\mathrm{H}^{+}$di dalam larutan tanah. Larutan tanah disebut bereaksi asam jika nilai $\mathrm{pH}$ berada pada kisaran 0-6 artinya larutan tanah mengandung ion $\mathrm{H}^{+}$lebih besar dari pada ion $\mathrm{OH}^{-}$sebaliknya jumlah ion $\mathrm{H}^{+}$dalam larutan tanah lebih kecil dari pada ion $\mathrm{OH}^{-}$larutan tanah ini disebut bereaksi basa (alkali) atau memiliki nilai $\mathrm{pH}$ 8-14. Jika jumlah ion $\mathrm{H}^{+}$di dalam larutan disebut bereaksi netral dengan nilai pH 7 (Novizan, 2002).

Tanah bersifat asam karena berkurangnya kation kalsium, magnesium, kaliun dan natrium. Unsurunsur tersebut terbawa oleh aliran air kelapisan tanah yang lebih bawah 
(pencucian) atau hilang diserap tanaman, karena ion-ion positif yang melekat pada koloid tanah berkurang, Kation membentuk asam seperti hidrogen dan aluminium akan menggantikannya. Terlalu banyak pupuk nitrogen seperti ZA juga menyebabkan peningkatan konsentrasi ion $\mathrm{H}^{+}$(Novizan, 2002). $\mathrm{pH}$ tanah dari sampel-sampel tanah yang diambil di Desa Detundora II disajikan pada tabel 4.2.5.

Pada tanah pertanian, $\mathrm{pH}$ tanah biasanya berkisar antara 4 hingga 8 .
Hampir semua tanah yang nilai $\mathrm{pH}$ nya di atas 8 memiliki kandungan $\mathrm{Na}+$ yang tinggi di dalam kompleks pertukaran kationnya; sedangkan tanah yang $\mathrm{pH}$ nya di bawa 4 biasanya kaya akan asam sulfat. Penilaian terhadap $\mathrm{pH}$ tanah adalah diperlukan untuk memberi gambaran tentang kondisi tanah pada saat itu. Salah satu cara penilaian $\mathrm{pH}$ ini adalah dengan menggunakan deskripsi pH seperti bagan berikut ini.

Tabel 8. Hasil Analisis pH Tanah

\begin{tabular}{|c|c|c|c|}
\hline No. Sampel & pH Tanah & No. Sampel & pH Tanah \\
\hline L.1.1.2 & 6,2 & L.2.13.2 & 5,6 \\
\hline L.1.2.2 & 5,4 & L.3.1.2 & 5,2 \\
\hline L.1.3.2 & 5,2 & L.3.2.2 & 5,6 \\
\hline L.1.4.2 & 5,4 & L.3.3.2 & 5,6 \\
\hline L.1.5.2 & 5,2 & L.3.4.2 & 5,2 \\
\hline L.1.6.2 & 4,6 & L.3.5.2 & 5,2 \\
\hline L.1.7.2 & 5 & L.3.6.2 & 5,2 \\
\hline L.1.8.2 & 5 & L.3.7.2 & 4,4 \\
\hline L.1.9.2 & 5,2 & L.3.8.2 & 4,8 \\
\hline L.1.10.2 & 5,2 & L.3.9.2 & 4,8 \\
\hline L.1.11.2 & 5,2 & L.3.10.2 & 5 \\
\hline L.1.12.2 & 5,2 & L.3.11.2 & 5,8 \\
\hline L.1.13.2 & 5,2 & L.3.12.2 & 4,8 \\
\hline L.2.1.2 & 5,6 & L.3.13.2 & 4,8 \\
\hline L.2.2.2 & 5,4 & L.4.1.2 & 4,6 \\
\hline L.2.3.2 & 5,6 & L.4.2.2 & 4,6 \\
\hline L.2.4.2 & 5,6 & L.4.3.2 & 5 \\
\hline L.2.5.2 & 6 & L.4.4.2 & 4,8 \\
\hline L.2.6.2 & 5,6 & L.4.5.2 & 4,6 \\
\hline L.2.7.2 & 5 & L.4.6.2 & 4,6 \\
\hline L.2.8.2 & 5,4 & L.4.7.2 & 4,4 \\
\hline L.2.9.2 & 5,2 & L.4.8.2 & 5 \\
\hline L.2.10.2 & 5,4 & L.4.9.2 & 4,4 \\
\hline L.2.11.2 & 5,4 & L.4.10.2 & 5 \\
\hline L.2.12.2 & 5,6 & L.4.11.2 & 4,4 \\
\hline
\end{tabular}




\section{SIMPULAN}

Hasil Penelitian analisis sifat fisik dan kimia tanah di Dusun Nuabosi Desa Ndetu Ndora I menunjukkan bahwa, tekstur tanah terdiri dari Lempung dan lempung berdebu. Pada struktur, jenis yang ada adalah struktur gumpak bersudut, gumpal membulat, granular, dan remah. Pada warna tanah didominasi oleh Very dark brown, dark brown, very dark gray, very dark grayish brown. Konsistensi tanah, terlihat bahwa tanahtanah tersebut mempunyai konsistensi lekat, plastis, gembur, lunak, $\mathrm{pH}$ yang ada pada tanah tersebut berkisar dari 4,86,4. Serta Kemiringan lereng berada pada kisaran $16 \%$ - $28 \%$.

\section{DAFTAR PUSTAKA}

Ali Hanafiah, Kemas. 2005. Dasar-Dasar Ilmu Tanah. Jakarta : CV. Raja Grafindo Persada.

Andersen, C.R. 2006. Mung bean Phaseolus Radiatus L. University of Arkansas, Arkansas, United States of America. Hilman, Y., A. Kasno, dan N. Saleh. 2004. Kacang kacangan dan umbi umbian: Kontribusi terhadap ketahanan pangan dan perkembangan teknologinya. Dalam makarim, et al. (penyunting), Inovasi Pertanian Tanaman Pangan. Puslitbangtan Bogor, 95132.

Anonim. 2011. Struktur Tanah. http://ariyantostaff.peratnian,UN S.14//Diakses pada selasa, 12 Mei 2014

Arsyad, S. 2000. Konservasi Tanah dan Air. Institut Pertanian Bogor Press. Bogor.
Ananto. 2010. Penentuan Dasar-Dasar Ilmu Tanah. Fakultas Pertanian Universitas Hasanuddin.

Arief, Saefudin. 1994. Ilmu Tanah Pertanian. Pustaka Buana Bandung

Foth, H.D. 1994. Dasar-Dasar Ilmu Tanah. Gajah Mada Universitas Press,

Foth, HD dan L.N.Turk. 1989. Fundamental of soils science. New York: fifth Ed.John.waley\&soil

Hanafiah, Ali Kemas. 2005. DasarDasar Ilmu Tanah. Raja Grafindo Persada : Jakarta.

Hardjowigeno. S., 1987. Ilmu Tanah. Penerbit Akademika Prassindo : Jakarta

Hardjowigeno. Sawono. 1992. Ilmu tanah. PT. Mediyatama sarana perkasa. Jakarta.

Hardjowigeno. S, 2003. Ilmu tanah. Akademi Pressindo. Jakarta

Hakim, dkk. 1986. Dasar-Dasar Ilmu Tanah. Universitas Lampung. Lampung.

Kartasapoetra, A. Gunarsih. 1986. Klimatologi: Pengaruh Iklim Terhadap Tanah dan Tanaman. Bumi Aksara. Jakarta

Kurnia. 2006. Ilmu Tanah. http://intl.Feedfury.com/conten/. Diakses tanggal 10 Mei 2014

Mawardi, M. 2011. Tanah - air tanaman : irigasi dan konservasi air. Bursa ilmu. Yogyakarta. 
Novizan. 2005. Petunjuk Pemupukan yang Efektif. Jakarta : Agromedia Pustaka. 114 hal.

Pairunan, A. 1985. Dasar-Dasar Ilmu Tanah. Badan Kerjasama Perguruan Tinggi Negeri Indonesia Timur: Makassar.

Rosmarkam, A. 2002. Ilmu Kesuburan Tanah. Yogyakarta: Kanisius. 224 hal.

Syafrina, S. 2009. Respon Pertumbuhan dan Produksi Kacang Hijau (Phaseolus Radiatus L.) pada Media Subsoil terhadap Pemberian Beberapa Jenis Bahan Organik dan Pupuk Organik Cair. http.www.google.com:repository. usu.ac.id. Diakses 11 November
2013. Novriani, 2011. Peranan Rhizobium dalam Meningkatkan Ketersediaan Nitrogen bagi Tanaman Kedelai.

Toha, H. M. K. Permadi., A.A. daradjat. 2008. Pengaruh Waktu Tanam Terhadap Pertumbuhan, Hasil dan Potensi Hasil Beberapa Varietas Padi Sawah Irigasi Dataran Rendah. http.www.google. Diakses 3 September 2013.

Winarso, S. 2005. Kesuburan Tanah. Gava Media. Yogyakarta. Susila, Anas D. 2006. Panduan Budidaya tanaman Sayuran. Bagian Produksi Tanaman Departemen Agronomi dan Hortikultura. Institut Pertanian Bogor. Bogor. 